\title{
Correction to: Cardiovascular causes of sudden unexpected death in children and adolescents (0-17 years)
}

\section{A nationwide autopsy study in the Netherlands}

\section{A. Vos (D) A. C. van der Wal · A. H. Teeuw - J. Bras - A. Vink · P. G. J. Nikkels · Dutch NODO group}

Published online: 8 January 2019

(c) The Author(s) 2018

\section{Correction to:}

\section{Neth Heart J 2018}

https://doi.org/10.1007/s12471-018-1152-y

In the version of the article originally published online, there was an error in the 'Methods and results' section of the Abstract. It is stated that 'In the 10-14 year group, hypertrophic cardiomyopathy $(n=1)$ and ruptured ascending aortic aneurysm $(n=1)$ were among the observed cardiovascular causes.'

The line should have read: 'In the 10-14 year group, coronary anomalies $(n=2)$ and arrhythmogenic cardiomyopathy $(n=1)$ were observed. In the 15-17 year group, hypertrophic cardiomyopathy $(n=1)$ and ruptured ascending aortic aneurysm $(n=1)$ were among the observed cardiovascular causes.'

\begin{abstract}
Open Access This article is distributed under the terms of the Creative Commons Attribution 4.0 International License (http://creativecommons.org/licenses/by/4.0/), which permits unrestricted use, distribution, and reproduction in any medium, provided you give appropriate credit to the original author(s) and the source, provide a link to the Creative Commons license, and indicate if changes were made.
\end{abstract}

A. Vos $(\bowtie) \cdot$ J. Bras · A. Vink · P. G. J. Nikkels

Department of Pathology, University Medical Center,

Utrecht, The Netherlands

a.vos-10@umcutrecht.nl

A. C. van der Wal $\cdot$ J. Bras

Department of Pathology, Academic Medical Center, Amsterdam, The Netherlands

\section{A. H. Teeuw}

Department of Paediatrics, Academic Medical Center,

Amsterdam, The Netherlands 